\title{
Joint analysis of selected GRACE monthly spherical harmonic solutions and monthly MASCON solutions
}

\author{
Adam NOVÁK (D) Juraj JANÁK* DD, Barbora KOREKÁČOVÁ (D) \\ Department of Theoretical Geodesy and Geoinformatics, Faculty of Civil Engineering, \\ Slovak University of Technology in Bratislava, \\ Radlinského 11, 81005 Bratislava, Slovak Republic
}

\begin{abstract}
Study presented in this paper is focused on comparison and statistical assessment of differences between the selected Level 2 products of the satellite mission Gravity Recovery and Climate Experiment (GRACE). Global monthly gravity field models in terms of spherical harmonic coefficients produced by three institutes of GRACE Science Data System are compared with the partially independent MASCON global gravity field model. Detailed comparison and statistical analysis of differences is performed in 5 selected river basins: Amazon, Congo, Danube, Yenisei and Lena. For each spherical harmonic solution, 8 different filtrations available at International Center for Global Gravity Field Models (ICGEM) are tested over the time span from April 2002 to July 2016. Fischer test at two significance levels $10 \%$ and $5 \%$ has been performed in order to qualify the statistical significance between the particular solutions.
\end{abstract}

Key words: time-variable gravity field, continental water storage, global geopotential models

\section{Introduction}

Very high precision and sensitivity of GRACE and GRACE-FO instruments, and thus very high inner precision of GRACE monthly gravity field solutions set up many challenges in hydrogeology, glaciology, meteorology, geophysics and geodesy. Hand in hand with the challenges, many questions have appeared concerning on interpretation, reliability of results and physical limitations of the mission. High inner precision introduced necessity of assuming many physical phenomena and very careful data processing.

There are many monthly gravity field solutions based on GRACE data, most of them are available through the International Center for Global Gravity Field Models (ICGEM) service, http://icgem.gfz-potsdam.de/

\footnotetext{
*corresponding author: e-mail: juraj.janak@stuba.sk
} 
series/, and many others are accessible via particular research centres. Official processing centres called Science Data System centres of the mission GRACE/GRACE-FO are Center for Space Research, University of Texas at Austin (CSR), https : //www . csr . utexas . edu/, Jet Propulsion Laboratory, California Institute of Technology (JPL), https : //www . jpl . nasa.gov/ and Deutsches GeoForschungsZentrum Potsdam (GFZ), https : //www.gfz-pot sdam.de/. There are many other research centres and universities worldwide compiling monthly gravity field solutions based on GRACE measurements.

There are two principally different procedures for compiling the monthly gravity field solution from GRACE data. First, and more commonly used procedure is based on spherical harmonic analysis, see e.g. Colombo (1981), Schmitz (1989) and the second, and more recent, procedure uses the mass concentration blocks method or MASCONs (Watkins et al., 2015). In this paper we will refer to this approaches as SH and MASCON, respectively. Both approaches have some advantages as well as limitations and in some aspects they may complement each other. Concerning on official SH solutions, there have been 6 releases up to now labelled RL01-RL06. In this paper we will deal with the latest RL06 published in 2018 described in Dahle et al. (2019) and Bettadpur (2018). All SH solutions based on GRACE data are affected by correlated noise demonstrated in form of meridian stripe pattern. To minimize this noise in data an appropriate filtering method needs to be used (Swenson and Wahr, 2006; Seo et al., 2008; Crowley and Huang, 2020). Depending on particular filter type and filter settings this can also lead to significant loss of gravity signal. The MASCON solutions are derived directly from the inter-satellite distance and don't require filtration. They use a different form of gravity field basis functions which enable more possibilities of direct implementation of geophysical constraints, see https://grace.jpl.nasa.gov/data/get-data/jpl_global mascons. MASCON solutions are mainly focused on variations of continental water storage, cryosphere variations and also on ocean bottom pressure variations.

Primary motivation for this work is to evaluate differences between two approaches based on GRACE satellite mission measurements, SH and MASCON. Secondary motivation is to compare SH solutions prepared by different Science Data System centres. Last but not least, our study is focused on comparison of SH solutions filtered using decorrelation filters DDK1 DDK8, see Kusche (2007) and Kusche et al. (2009) with the unfiltered 
MASCON solutions.

\section{Selection of test areas and input data description}

In order to perform detailed testing but on the same time representative enough for general conclusion, we chose five river basins in four different continents as our test areas: Amazon basin, Danube basin, Congo basin, Yenisei basin and Lena basin, see Fig. 1. More details about river basins can be found in Interactive Database of the World's River Basins at http://riverbasins. wateractionhub.org/.

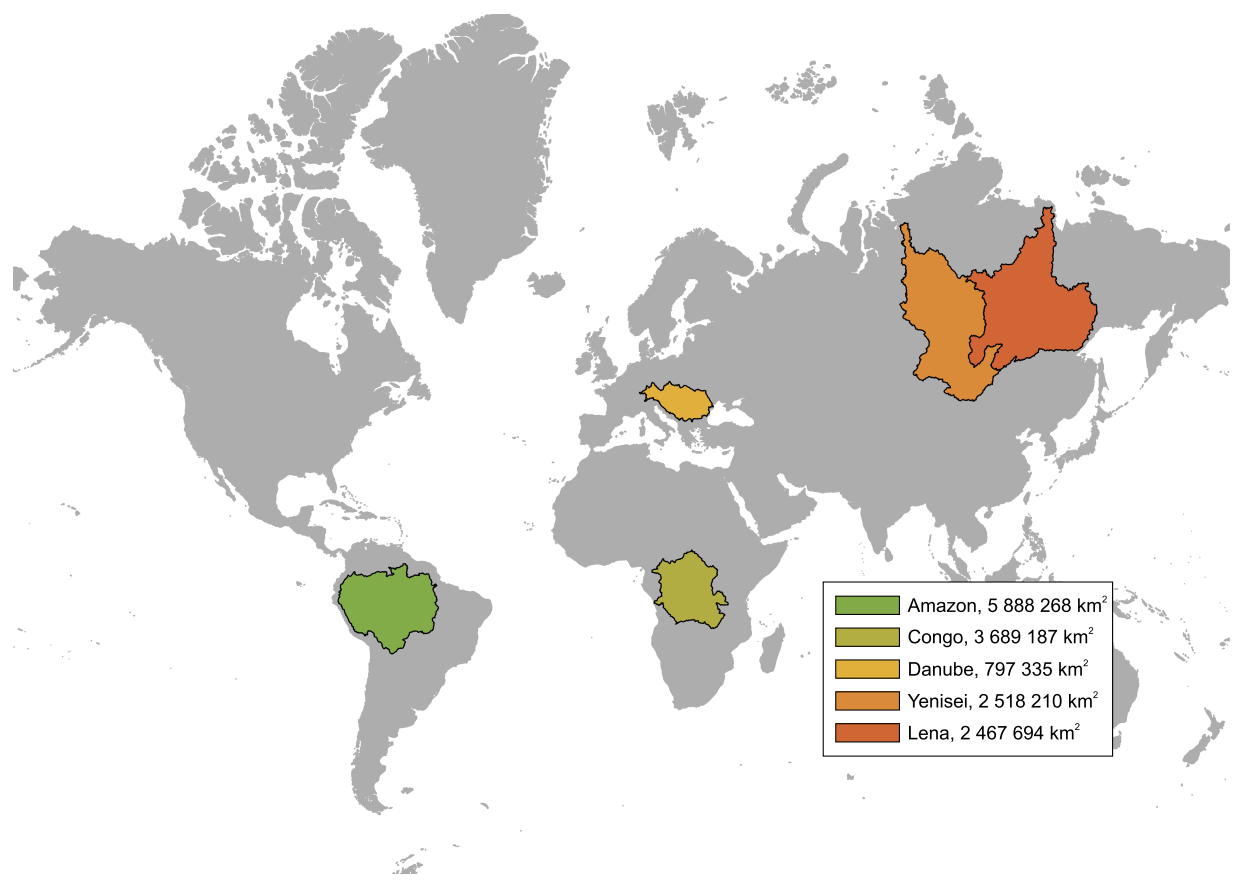

Fig. 1. Selected river basins as our test areas together with information about the surface extent.

Selection of the test areas was led by the idea to alternate different climatic conditions, different typical amplitude of the seasonal signal and different surface extent. We chose basins with minimal length of coastal boundary to minimize the leakage effect in $\mathrm{SH}$ approach. Amazon and Congo basins were chosen for their vast drainage area, tropical climate and 
thus large seasonal amplitudes. Danube basin was chosen for its smaller area and moderate climate with typical four season changes. Yenisei and Lena basins represent higher latitude areas with lower seasonal variations.

Reference input data in our study were $1^{\circ}$ equal-area spherical cap MASCON monthly solutions GSFC.glb.200301_201607_v02.4 available at the web page of Goddard Space Flight Center (GSFC) https://earth.gsfc .nasa. gov/geo/data/grace-mascons, see Luthcke et al. (2013). According to the web-page it is the standard solution, not corrected for glacial isostatic adjustment (GIA) effect and thus comparable to GRACE Project Level-2 SH solution. This data product is available in monthly grids with $1^{\circ} \times 1^{\circ}$ resolution. An average model from the period 2004.0-2016.0 is automatically subtracted so the grids represent the time variations of continental water storage in equivalent water thickness (EWT), see Eq. (1), with regards to long-term average. This MASCON product also contains statistical uncertainties including the leakage effect. We used these uncertainties for computation of confidence interval of reference solution in our comparison.

Test input data in our study were GRACE RL06 SH monthly solutions from the Science Data System centres GFZ, CSR and JPL provided by ICGEM service, see Dahle et al. (2019) and Bettadpur (2018). We decided to use the version with the higher spatial resolution containing the global spherical harmonic coefficients up to degree and order (d/o) 96. Coefficients $C_{2,0}$ were not replaced from Satellite Laser Ranging but the original GRACE-based $C_{2,0}$ coefficients were used in order to test the original DDK filtered models provided by ICGEM service. All models are in zero-tide system. All 8 DDK filters were tested. Figure 2 shows the availability of particular input data.

\section{Preparation of the time series}

First, the global grids of EWT, with $1^{\circ} \times 1^{\circ}$ resolution in spherical latitude and longitude, were computed from GRACE RL06 SH monthly solutions using Graflab software running on Matlab platform, see Bucha and Janák (2013). All grids were computed up to full $\mathrm{d} / \mathrm{o}=96$. Only those months when all three solutions were available, see Fig. 2, were selected. In total, it was 154 months from April 2002 to June 2017. However, the number of months with all SH and MASCON solutions is only 137. The longest period 


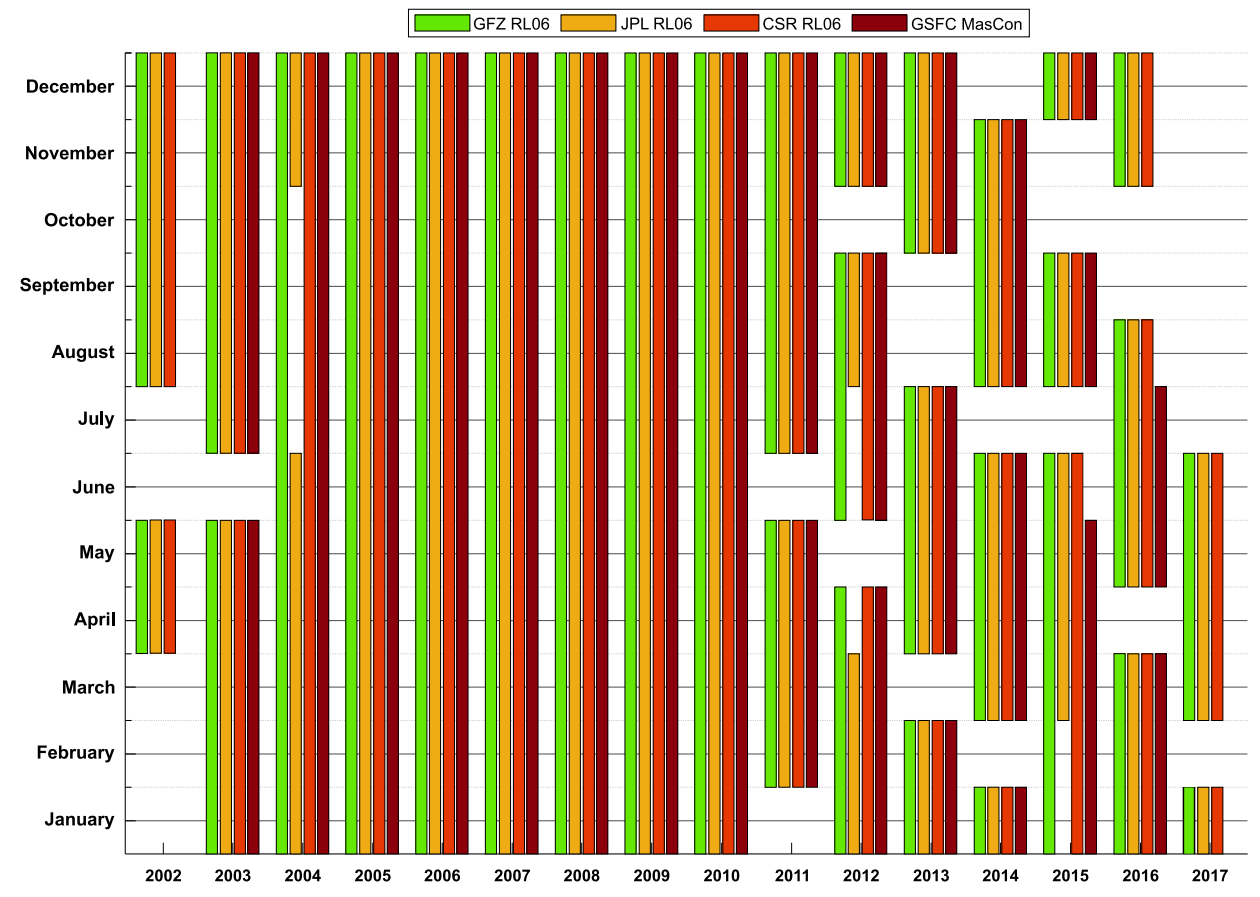

Fig. 2. Availability of particular GRACE RL06 SH and MASCON input data.

without any interruption is 74 months from November 2004 to December 2010 .

The formula used for EWT computation from SH coefficients can be found e.g. in Wahr et al. (1998), see Eq. (1):

$$
\begin{array}{r}
E W T=\frac{R \cdot \rho_{a v}}{3} \sum_{n=0}^{n_{\max }} \frac{2 n+1}{1+k_{n}} \sum_{k=0}^{n}\left[J_{n k} \cdot \cos (k \cdot \lambda)+S_{n k} \cdot \sin (k \cdot \lambda)\right] \times \\
\times \bar{P}_{n k}(\sin (\varphi))
\end{array}
$$

where $R$ is Earth's equatorial radius, $\rho_{a v}$ is mean Earth's density, $n, k$ are degree and order of SH coefficients, $k_{n}$ are degree-dependent Love numbers, $J_{n k}, S_{n k}$ are fully-normalized $\mathrm{SH}$ coefficients, $\bar{P}_{n k}(\sin (\varphi))$ is normalized Legendre associated function of degree $n$ and order $k$ and $\varphi, \lambda$ are spherical coordinates latitude and longitude. Physical unit of $E W T$ computed by Eq. (1) is $\left[\mathrm{kg} \cdot \mathrm{m}^{-2}\right]$ which corresponds to millimetres of water column provided that the water density is $1000 \mathrm{~kg} \cdot \mathrm{m}^{-3}$. 
The mean models of each particular SH solution and filtration were computed as a simple average of all grids in selected months. For every solution, its own mean model, yet computed from the same months, was used to get the monthly time variations with respect to the long-term mean, see Janák (2020). The corresponding mean models were subtracted from every monthly SH solution obtaining the quantity denoted as $\Delta E W T_{i j k}$. The indices $i$ stands for the computation centre, $j$ is the number of the filter and $k$ is the number of the test area. We tested solutions from 3 computation centres, 8 filtrations from each centre in 5 different test areas so in total we got 120 sets, or grids, of $\Delta E W T$ plus five reference solutions of $\Delta E W T$ for each test area coming from the MASCON solution.

In order to compare and assess the $\mathrm{SH}$ solutions in terms of $\Delta E W T$, we generated the differences between the corresponding months of SH and MASCON grids. An example of one particular SH solution GFZ RL06 DDK1 averaged for the Danube basin together with the reference GSFC MASCON solution and its statistical uncertainty $( \pm 2 \sigma)$ is shown in Fig. 3 - top graph. Differences where the reference solution is subtracted from
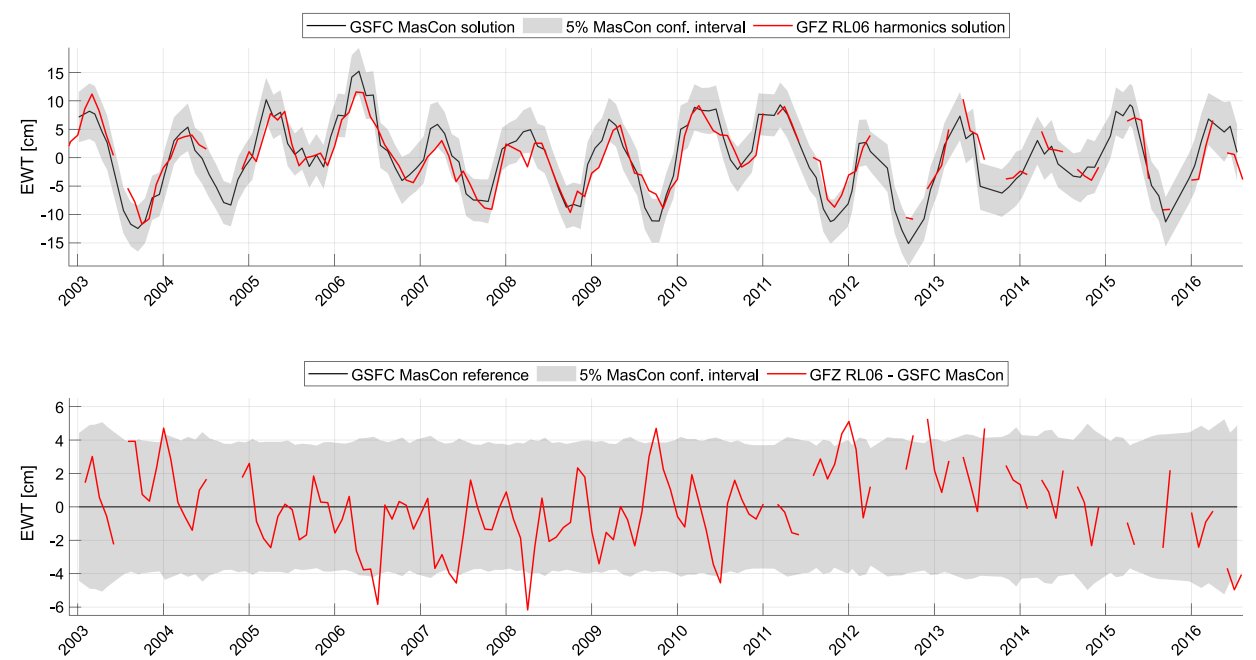

Fig. 3. Graphical example computed for Danube basin demonstrating our experiment: SH GFZ RL06 DDK1 solution (red line) compared to reference MASCON solution (gray line). Confidence interval $( \pm 2 \sigma)$ for the MASCON solution is shown by light gray color belt. Bottom graph shows the differences of SH minus MASCON solutions. 
the test solution are shown in Fig. 3 - bottom graph, together with the statistical uncertainty $( \pm 2 \sigma)$ of the reference model.

\section{Statistical assessment}

Obtained differences have been evaluated using two criteria. The first criterion was the percentage of monthly differences which lies within the uncertainty interval $( \pm 2 \sigma)$ of the reference solution. The larger the value, the better agreement and the more credible solution. The second criterion was the standard deviation of the differences $\sigma_{\text {diff }}$. Using this criterion, the smaller the value, the better agreement and thus the more credible solution. For each test area two histograms, see Figs. 4-6, have been plotted corre-
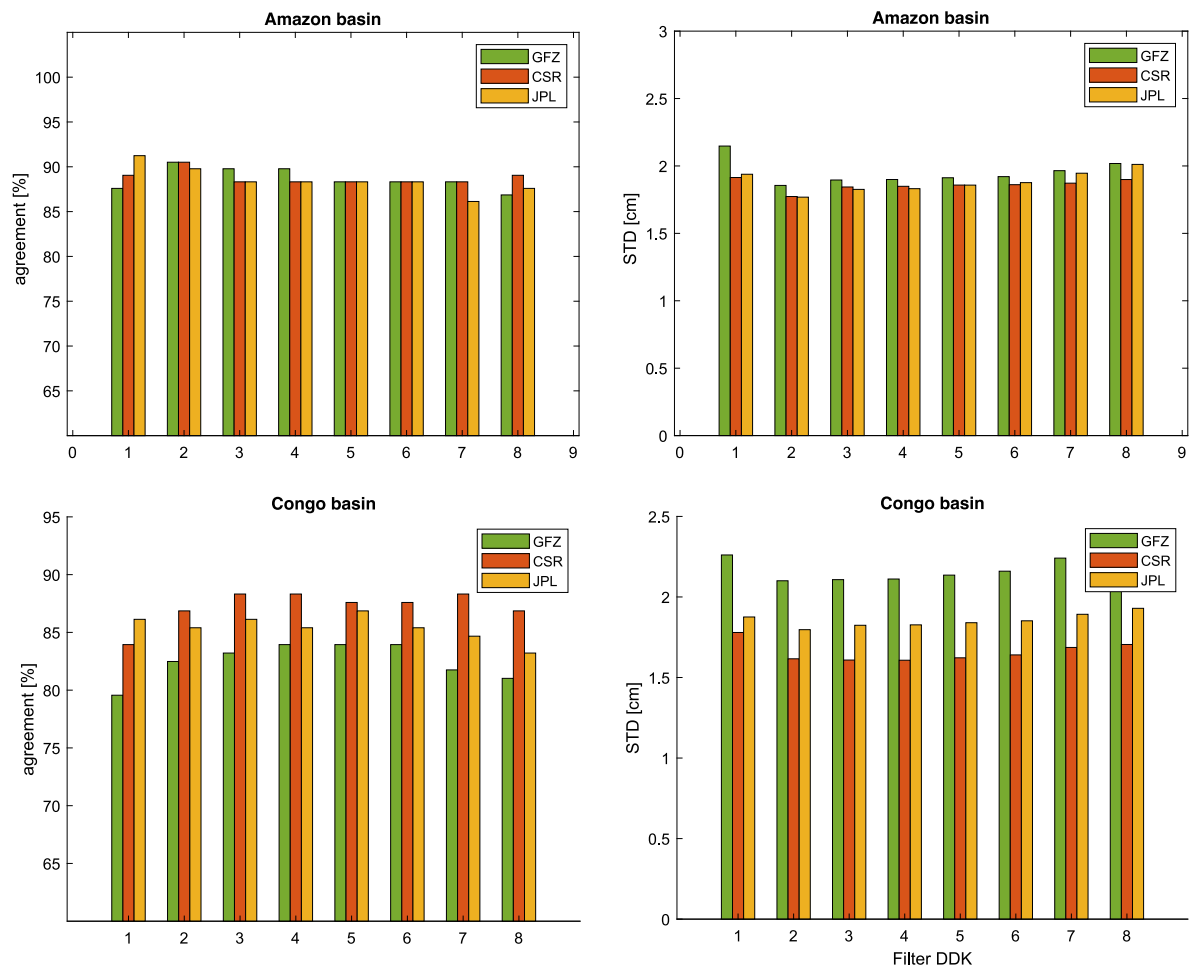

Fig. 4. Histograms showing the percentage of differences within $2 \sigma$ uncertainty interval of reference MASCON solution (left) and standard deviations of differences (right) for tropical Amazon and Congo basins. 

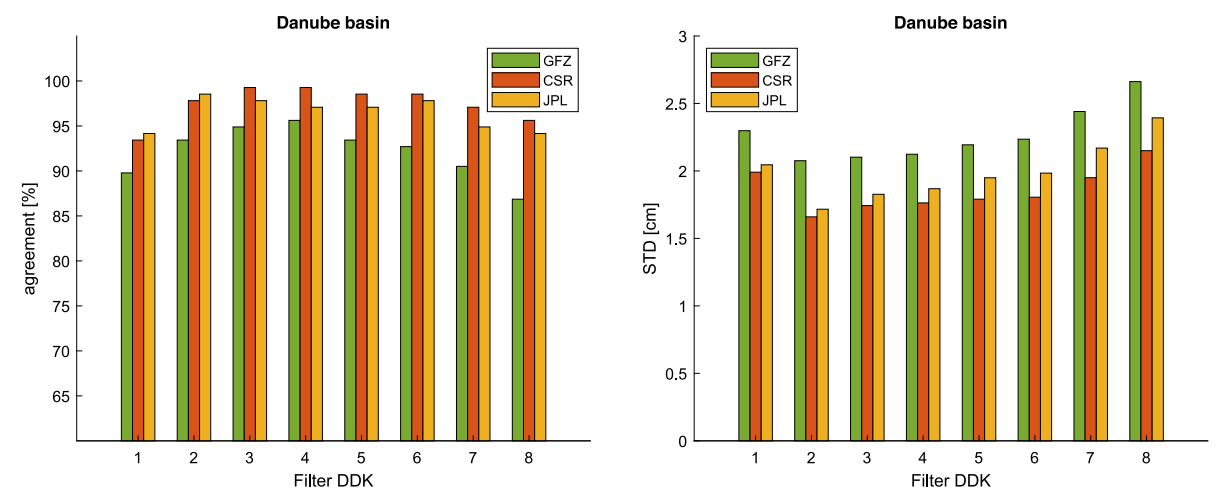

Fig. 5. Histograms showing the percentage of differences within $2 \sigma$ uncertainty interval of reference MASCON solution (left) and standard deviations of differences (right) for moderate climate Danube basin.
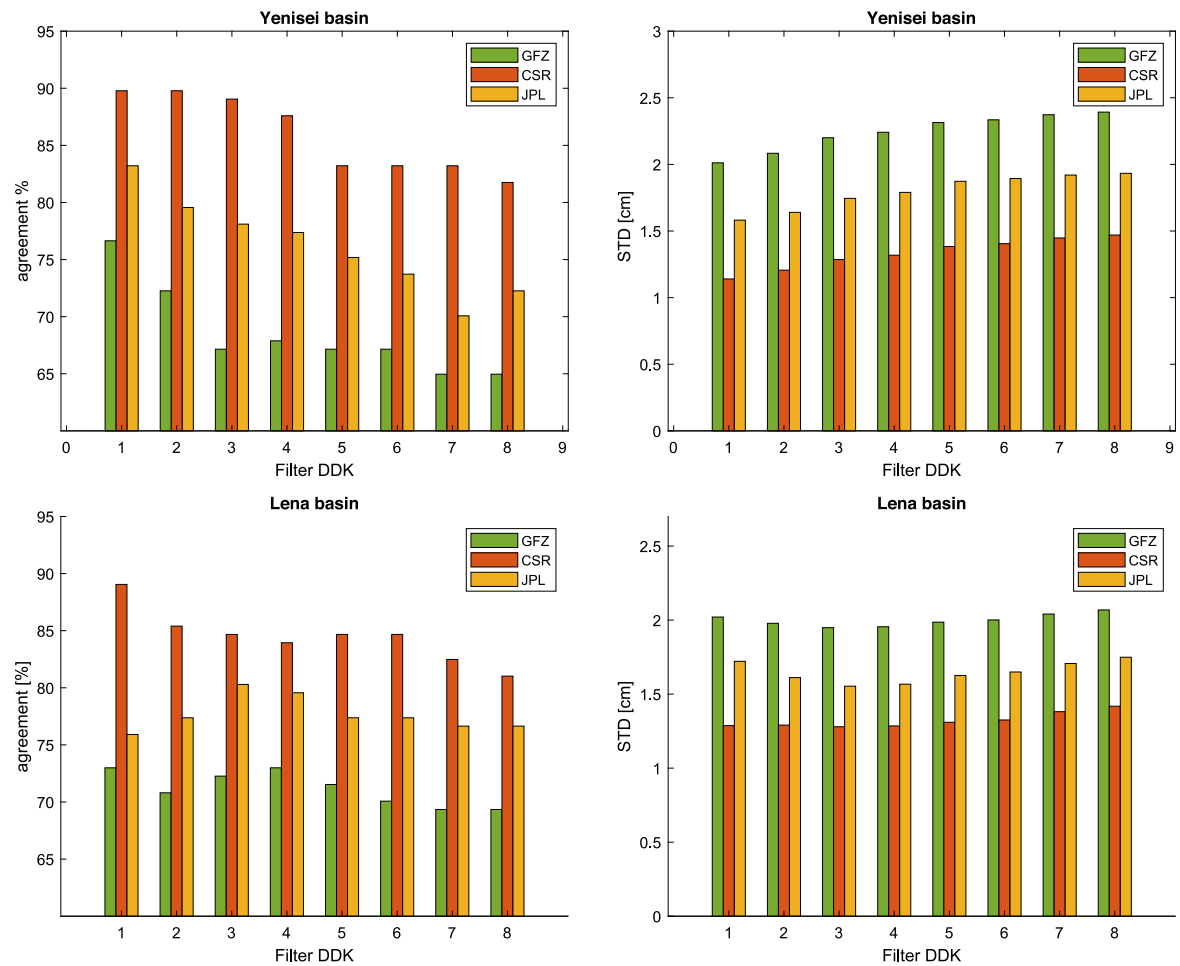

Fig. 6. Histograms showing the percentage of differences within $2 \sigma$ uncertainty interval of reference MASCON solution (left) and standard deviations of differences (right) for cooler climate Yenisei and Lena basins. 
sponding to two criteria. Fig. 4 is dedicated to Amazon and Congo basins with several common features: vast drainage area, tropical climate and large seasonal variations. Fig. 5 shows the Danube basin with smaller drainage area and moderate climate and Fig. 6 depicts the Yenisei and Lena basins with cooler climate and smaller seasonal variations. Numerical results are shown in Tables 1-3.

Analysing the histograms shown in Figs. 4-6 together with the numerical values presented in Tables 1-3 we can see some interesting findings.

- Results from the river basins with the similar climatic conditions do not necessarily behave similarly. They can be quite different.

- Following the standard deviation criterion (left histograms and left part of the tables) we see that the best agreement with the reference MASCON

Table 1. Results of testing in large tropical basins. Dark grey fields mark the best filtration for particular solutions and light grey fields with bold mark the best solution for particular basin according to first criterion (left part of the table) and second criterion (right part of the table).

\begin{tabular}{|c|c|c|c|c|c|c|}
\hline \multicolumn{7}{|c|}{ Amazon } \\
\hline & GFZ(\%) & CSR(\%) & JPL(\%) & GFZ(cm) & CSR(cm) & JPL(cm) \\
\hline DDK1 & 87.6 & 89.1 & 91.2 & 2.15 & 1.91 & 1.94 \\
\hline DDK2 & 90.5 & 90.5 & 89.8 & 1.86 & 1.77 & 1.77 \\
\hline DDK3 & 89.8 & 88.3 & 88.3 & 1.90 & 1.84 & 1.83 \\
\hline DDK4 & 89.8 & 88.3 & 88.3 & 1.90 & 1.85 & 1.83 \\
\hline DDK5 & 88.3 & 88.3 & 88.3 & 1.91 & 1.86 & 1.86 \\
\hline DDK6 & 88.3 & 88.3 & 88.3 & 1.92 & 1.86 & 1.88 \\
\hline DDK7 & 88.3 & 88.3 & 86.1 & 1.97 & 1.87 & 1.95 \\
\hline DDK8 & 86.9 & 89.1 & 87.6 & 2.02 & 1.90 & 2.01 \\
\hline \multicolumn{7}{|c|}{ Congo } \\
\hline & GFZ(\%) & CSR(\%) & JPL(\%) & GFZ(cm) & CSR(cm) & JPL(cm) \\
\hline DDK1 & 79.6 & 83.9 & 86.1 & 2.26 & 1.78 & 1.88 \\
\hline DDK2 & 82.5 & 86.9 & 85.4 & 2.10 & 1.62 & 1.80 \\
\hline DDK3 & 83.2 & 88.3 & 86.1 & 2.11 & 1.61 & 1.82 \\
\hline DDK4 & 83.9 & 88.3 & 85.4 & 2.11 & 1.61 & 1.83 \\
\hline DDK5 & 83.9 & 87.6 & 86.9 & 2.14 & 1.62 & 1.84 \\
\hline DDK6 & 83.9 & 87.6 & 85.4 & 2.16 & 1.64 & 1.85 \\
\hline DDK7 & 81.8 & 88.3 & 84.7 & 2.24 & 1.69 & 1.89 \\
\hline DDK8 & 81.0 & 86.9 & 83.2 & 2.29 & 1.71 & 1.93 \\
\hline
\end{tabular}


Table 2. Results of testing in moderate climate basin. Dark grey fields mark the best filtration for particular solutions and light grey fields with bold mark the best solution for particular basin according to first criterion (left part of the table) and second criterion (right part of the table).

\begin{tabular}{|c|c|c|c|c|c|c|}
\hline \multicolumn{7}{|c|}{ Danube } \\
\hline & GFZ(\%) & CSR(\%) & JPL(\%) & GFZ(cm) & CSR(cm) & JPL(cm) \\
\hline DDK1 & 89.8 & 93.4 & 94.2 & 2.30 & 1.99 & 2.05 \\
\hline DDK2 & 93.4 & 97.8 & 98.5 & 2.08 & 1.66 & 1.72 \\
\hline DDK3 & 94.9 & 99.3 & 97.8 & 2.10 & 1.74 & 1.83 \\
\hline DDK4 & 95.6 & 99.3 & 97.1 & 2.12 & 1.76 & 1.87 \\
\hline DDK5 & 93.4 & 98.5 & 97.1 & 2.19 & 1.79 & 1.95 \\
\hline DDK6 & 92.7 & 98.5 & 97.8 & 2.24 & 1.81 & 1.98 \\
\hline DDK7 & 90.5 & 97.1 & 94.9 & 2.44 & 1.95 & 2.17 \\
\hline DDK8 & 86.9 & 95.6 & 94.2 & 2.66 & 2.15 & 2.39 \\
\hline
\end{tabular}

Table 3. Results of testing in cooler climate basin. Dark grey fields mark the best filtration for particular solutions and light grey fields with bold mark the best solution for particular basin according to first criterion (left part of the table) and second criterion (right part of the table).

\begin{tabular}{|c|c|c|c|c|c|c|}
\hline \multicolumn{7}{|c|}{ Yenisei } \\
\hline & GFZ(\%) & CSR(\%) & JPL(\%) & GFZ(cm) & CSR(cm) & JPL(cm) \\
\hline DDK1 & 76.6 & 89.8 & 83.2 & 2.01 & 1.14 & 1.58 \\
\hline DDK2 & 72.3 & 89.8 & 79.6 & 2.08 & 1.21 & 1.64 \\
\hline DDK3 & 67.2 & 89.1 & 78.1 & 2.20 & 1.29 & 1.75 \\
\hline DDK4 & 67.9 & 87.6 & 77.4 & 2.24 & 1.32 & 1.79 \\
\hline DDK5 & 67.2 & 83.2 & 75.2 & 2.31 & 1.38 & 1.87 \\
\hline DDK6 & 67.2 & 83.2 & 73.7 & 2.33 & 1.41 & 1.89 \\
\hline DDK7 & 65.0 & 83.2 & 70.1 & 2.37 & 1.45 & 1.92 \\
\hline DDK8 & 65.0 & 81.8 & 72.3 & 2.39 & 1.47 & 1.93 \\
\hline \multicolumn{7}{|c|}{ Lena } \\
\hline & GFZ(\%) & CSR(\%) & JPL(\%) & GFZ(cm) & CSR(cm) & JPL(cm) \\
\hline DDK1 & 73.0 & 89.1 & 75.9 & 2.02 & 1.29 & 1.72 \\
\hline DDK2 & 70.8 & 85.4 & 77.4 & 1.98 & 1.29 & 1.61 \\
\hline DDK3 & 72.3 & 84.7 & 80.3 & 1.95 & 1.28 & 1.55 \\
\hline DDK4 & 73.0 & 83.9 & 79.6 & 1.96 & 1.29 & 1.57 \\
\hline DDK5 & 71.5 & 84.7 & 77.4 & 1.99 & 1.31 & 1.63 \\
\hline DDK6 & 70.1 & 84.7 & 77.4 & 2.00 & 1.33 & 1.65 \\
\hline DDK7 & 69.3 & 82.5 & 76.6 & 2.04 & 1.38 & 1.71 \\
\hline DDK8 & 69.3 & 81.0 & 76.6 & 2.07 & 1.42 & 1.75 \\
\hline
\end{tabular}


solution is provided by the SH solution compiled by CSR centre. This holds in all 5 tested river basins but it is especially apparent for cooler climate basins Yenisei and Lena.

- Corresponding SH solutions from all centres are very similar in Amazon basin.

- In 3 test areas the best performance showed DDK2 filtration, in one DDK1 and in one DDK3 filtration.

- Standard deviations of SH CSR solution differences with respect to MASCON solutions vary from $1.14 \mathrm{~cm}$ (Yenisei) to $1.77 \mathrm{~cm}$ (Amazon).

- Standard deviations of SH JPL solution differences with respect to MASCON solutions vary from $1.55 \mathrm{~cm}$ (Lena) to $1.80 \mathrm{~cm}$ (Congo).

- Standard deviations of SH GFZ solution differences with respect to MASCON solutions vary from $1.86 \mathrm{~cm}$ (Amazon) to $2.10 \mathrm{~cm}$ (Congo).

- Percentage of agreement between the SH and MASCON solutions, assuming the best filtration, vary from $73.0 \%$ (GFZ DDK1 and DDK4 in Lena basin) to $99.3 \%$ (CSR DDK3 and DDK4 in Danube basin).

The mean differences of $\Delta E W T$ between the SH and MASCON solutions were also evaluated. Results of the best filtration for particular test areas and computation centres are shown in Table 4.

Table 4. Mean differences between the SH and MASCON solutions for particular river basins and computation centres. Only the results of the best filtrations are shown. Units: $\mathrm{cm}$.

\begin{tabular}{|c|c|c|c|c|c|}
\hline & Amazon & Congo & Danube & Yenisei & Lena \\
\hline GFZ & 0.55 & -0.83 & -0.01 & 0.1 & 0.61 \\
\hline CSR & 0.65 & -0.76 & -0.02 & 0.11 & 0.39 \\
\hline JPL & 0.73 & -0.76 & -0.05 & 0.02 & 0.35 \\
\hline
\end{tabular}

Based on the results shown in Table 4 we see that the mean differences vary from basin to basin while in one basin they are similar for all centres. This indicates some long-wavelength locally systematic effect either in $\mathrm{SH}$ or in MASCON solutions, or in both.

Numerical tests revealed that some SH solutions are better than others, in terms of agreement with the MASCON solution, in particular basins. However, in order to see the statistical significance of the differences between the solutions we performed the Fisher statistical test at two significance levels $10 \%$ and 5\%. Results are shown in Fig. 7. Test compares the dispersion of 
differences ( $\mathrm{SH}-\mathrm{MASCON}$ ) of the best $\mathrm{SH}$ solution in particular river basin to dispersions of differences of all other solutions. Red and blue horizontal
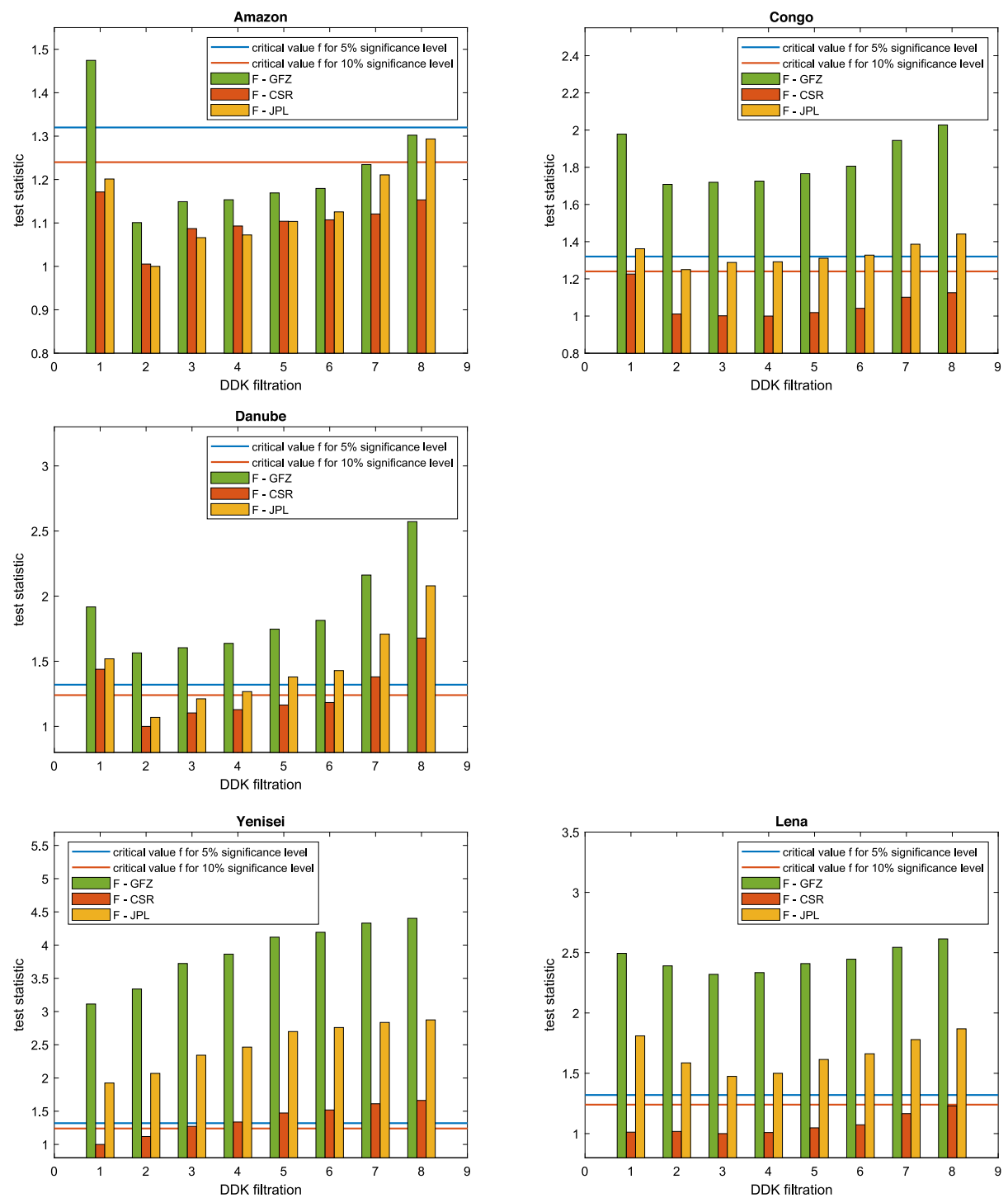

Fig. 7. Values of test statistics of Fischer statistical test for all performed SH solutions in particular river basins. Critical values for $10 \%$ and $5 \%$ significance levels are shown by red and blue horizontal lines, respectively. 
lines represent the critical values of the test statistics for the significance level $10 \%$ or $5 \%$ respectively. The best solution in particular river basin, see Tables 1-3, has the value of test statistics equal to 1 . Other solutions are always compared to this solution. Differences of those solutions which are above the critical values are statistically significant with probability $90 \%$ or $95 \%$, respectively.

Based on graphs in Fig. 7 we can see that the smallest differences between the $\mathrm{SH}$ solutions are in the Amazon basin and largest in the Yenisei basin. If we choose the $5 \%$ significance level, we see that in the Amazon basin the only solution which exceeded the critical value is GFZ DDK1 and thus only this solution can be considered significantly different from the best solution (in terms of agreement with the MASCON solution) which is CSR DDK2. In contrast, in Yenisei basin most of the solutions exceeded the critical value, except the CSR DDK2 and CSR DDK3 when comparing to the best solution, which is CSR DDK1. In the Lena basin, none of the CSR solutions but all of the GFZ and JPL solutions regardless of the filtration are considered to be significantly different than the best solution CSR DDK3. In the Danube basin the situation is more complex. Some filtrations, even from the same processing centre as the best solution which is CSR DDK2, exceeded the critical value and other not. In the Congo basin, the best solution is CSR DDK3 and solutions exceeding the $5 \%$ critical value are JPL DDK1, DDK6, DDK7, DDK8 and all GFZ solutions.

Comparing the $\mathrm{SH}$ solutions from different processing centres we see that CSR solutions are in most cases in the best agreement with the MASCON solution and GFZ solutions differ from the MASCON solution the most in all studied basins and for all filtration parameters.

\section{Conclusion}

GRACE and GRACE-FO missions have been producing valuable data with unprecedented accuracy, yet degraded with a correlated noise. Our paper aimed to contribute to experimental research in order to get the best-quality physical signal out of the GRACE monthly solutions produced by GRACE Science Data System centres. In our experiment we chose the MASCON GSFC solution to be the reference to which other SH solutions were compared. We used the advantage of MASCON different processing strategy 
free from errors coming from decorrelation and filtering procedures. However, we must not forget that our reference solution is not error-free. Having this in mind, we need to be careful in final interpretation of our results. Looking at our results we are able to formulate several conclusion remarks.

- In most cases the anisotropic filtration method assigned as DDK2, see Tables $1-3$, produced the best results.

- Depending on location, the SH solutions prepared by different entities of GRACE Science Data System can give us statistically significantly different results. While in some river basins, e.g. Amazon, the SH solutions from all centres are very similar, in other basins, e.g. Yenisei, the differences are remarkable and statistically significant, see Fig. 7.

- SH solutions produced by CSR centre provide the best agreement with the MASCON GSFC solution.

- Results coming from neighbouring river basins or river basins with similar climatic conditions can be very different.

- The mean differences of $\Delta E W T$ between the SH and MASCON solutions vary from basin to basin while in one basin they are similar for all centres, see Table 4. This indicates the presence of some systematic effect in one of the solutions.

Acknowledgements. Research presented in this paper was prepared with the support of the grant VEGA 1/0750/18 Analysis of selected geodynamical processes using absolute and relative gravimetry and GNSS technology.

\section{References}

Bettadpur S., 2018: Gravity Recovery and Climate Experiment, Level-2 gravity field product user handbook. Center for Space Research at the University of Texas at Austin, https://podaac-tools.jpl.nasa.gov/drive/files/allData/grace/docs/L2-Use rHandbook_v4.0.pdf.

Bucha B., Janák J., 2013: A MATLAB-based graphical user interface program for computing functionals of the geopotential up to ultra-high degrees and orders. Comput. Geosci., 56, 186-196, doi: 10.1016/j.cageo.2013.03.012.

Colombo O. L., 1981: Numerical Methods for Harmonic Analysis on the Sphere. Ohio State Univ. Dept. Geod. Sci,. Report No. 310.

Crowley J. W., Huang J., 2020: A least-squares method for estimating the correlated error of GRACE models. Geophys. J. Int., 211, 3, 1736-1749, doi: 10.1093/gji/ggaa104. 
Dahle Ch., Murböck M., Flechtner F., Dobslaw H., Michalak G., Neumayer K. H., Abrykosov O., Reinhold A., König R., Sulzbach R., Förste Ch., 2019: The GFZ GRACE RL06 monthly gravity field time series: Processing details and quality assessment. Remote Sens., 11, 18, 2116, doi: 10.3390/rs11182116.

Janák J., 2020: Comparison of different GRACE monthly gravity field solutions. In: Advances and Trends in Geodesy, Cartography and Geoinformatics II, Proceedings on 11th International Scientific and Professional Conference on Geodesy, Cartography and Geoinformatics (GCG 2019), September 10-13, 2029, Demänovská dolina, Low Tatras, Slovakia, CRC Press, London, e-ISBN 9780429327025, 116-122, doi: 10.12 01/9780429327025.

Kusche J., 2007: Approximate decorrelation and non-isotropic smoothing of time-variable GRACE-type gravity field models. J. Geod, 81, 11, 733-749, doi: 10.1007/s00190007-0143-3.

Kusche J., Schmidt R., Petrovic S., Rietbroek R., 2009: Decorrelated GRACE timevariable gravity solutions by GFZ, and their validation using a hydrological model. J. Geod., 83, 10, 903-913, doi: 10.1007/s00190-009-0308-3.

Luthcke S. B., Sabaka T. J., Loomis B. D., Arendt A. A., McCarthy J. J., Camp J., 2013: Antarctica, Greenland and Gulf of Alaska land ice evolution from an iterated GRACE global mascon solution. J. Glaciol., 59, 216, 613-631, doi : 10.3189/2013Jo G12J147.

Schmitz D., 1989: Spherical harmonic analysis. In: James D. E. (Ed.): Geophysics. Encyclopedia of Earth Science. Springer, Boston, MA, doi : 10.1007/0-387-30752-4_146.

Seo K.-W., Wilson C. R., Chen J., Waliser D. E., 2008: GRACE's spatial aliasing error. Geophys. J. Int., 172, 1, 41-48, doi: 10.1111/j.1365-246X.2007.03611.x.

Swenson S., Wahr J., 2006: Post-processing removal of correlated errors in GRACE data. Geophys. Res. Lett., 33, 8, L08402, doi: 10.1029/2005GL025285.

Wahr J., Molenaar M., Bryan F., 1998: Time variability of the Earth's gravity field: Hydrological and oceanic effects and their possible detection using GRACE. J. Geophys. Res. Solid Earth, 103, B12, 30205-30229, doi: 10.1029/98JB02844.

Watkins M. M., Wiese D. N., Yuan D.-N., Boening C., Landerer F. W., 2015: Improved methods for observing Earth's time variable mass distribution with GRACE using spherical cap mascons. J. Geophys. Res. Solid Earth, 120, 4, 2648-2671, doi: 10. 1002/2014JB011547. 